\title{
Characterisation of expression patterns and functional role of Cactin in early zebrafish development
}

\author{
Paola Atzei ${ }^{\text {a }}$, Fan Yang ${ }^{\text {b }}$, Ross Collery ${ }^{\mathrm{b}}$, Breandan N. Kennedy ${ }^{\mathrm{b}, 1}$, Paul N. Moynagh ${ }^{\mathrm{a}, *, 1}$ \\ a Institute of Immunology, National University of Ireland Maynooth, Maynooth, Co. Kildare, Ireland \\ ${ }^{\mathrm{b}}$ UCD School of Biomolecular and Biomedical Sciences, UCD Conway Institute, University College Dublin, Dublin 4, Ireland
}

\section{A R T I C L E I N F O}

\section{Article history:}

Received 21 December 2009

Received in revised form 12 March 2010

Accepted 19 March 2010

Available online 27 March 2010

\section{Keywords:}

Toll-like receptors

$\mathrm{NF}-\mathrm{KB}$

Cactin

Early development

In situ hybridisation

Morpholino

\begin{abstract}
A B S T R A C T
The immune system of teleost zebrafish (Danio rerio) shows high similarity to mammalian counterparts sharing many innate immune components including Toll-Like Receptors (TLRs), cytokines, chemokines and complement molecules. As in mammals, zebrafish also contains the transcription factor NF- $\kappa \mathrm{B}$ that plays dualist roles in innate immunity and early development. Indeed NF- $\kappa B$ members are expressed in different temporal patterns during the early stages of zebrafish embryogenesis indicating that each molecule is involved in specific developmental events. In the present study we employ zebrafish as a model to characterise the expression pattern and role of a novel NF- $\kappa B$ regulator, termed Cactin, in early development. Cactin was first characterised in Drosophila as a new member of the Rel pathway that could affect the generation of dorsal-ventral polarity. To explore the potential developmental role of Cactin in zebrafish, we initially investigated its expression pattern and functional role during early embryonic developmental stages. We detect Cactin expression at all stages of early development and knockdown of Cactin by specific morpholino antisense oligonucleotides causes developmental abnormalities manifested by an overall dysmorphic cellular organisation. These results indicate that Cactin has been highly conserved during evolution and plays a key role in early embryonic development.
\end{abstract}

() 2010 Elsevier B.V. All rights reserved.

\section{Results and discussion}

The transcription factor NF- $\kappa$ B plays a key role in regulating the innate and adaptive arms of the immune system (Hayden et al., 2006; Vallabhapurapu and Karin, 2009). However members of the NF- $\kappa$ B family have also been demonstrated to act as important regulators of early Drosophila development (Govind, 1999). Such dualist roles for NF- $\kappa \mathrm{B}$ in immunity and development have led to intense investigation on the signalling pathways that regulate its activation. Inhibitory roles have been described for $\mathrm{I}-\kappa \mathrm{B}$ proteins that bind directly to NF- $\kappa \mathrm{B}$ subunits and block activation of the latter by sequestering them in the cytoplasm and inhibiting their DNA-binding capacity (Moynagh, 2005). Various immune and developmental stimuli activate NF- $\kappa \mathrm{B}$ by triggering signalling cascades that culminate in phosphorylation of $\mathrm{I}-\kappa \mathrm{B}$ proteins leading to their ubiquitination and proteasome-mediated degradation. The proteolysis of $\mathrm{I}-\kappa \mathrm{Bs}$ allows for nuclear translocation of NF- $\kappa \mathrm{B}$ and its activation of transcription of a plethora of genes including ones that promote the generation of dorso-ventral polarity in early development. Given the highly conserved nature of the NF- $\kappa \mathrm{B} / \mathrm{I}-\kappa \mathrm{B}$

\footnotetext{
* Corresponding author. Tel.: +3531 708 6105; fax: +3531 7086337 .

E-mail address: Paul.Moynagh@nuim.ie (P.N. Moynagh).

1 These authors contributed equally to this work.
}

families Drosophila has served as a highly valuable model organism in defining the early developmental role of NF- $\mathrm{BB}$ (Govind, 1999; Minakhina and Steward, 2006). Thus dorsal, the NF- $\mathrm{BB}$ homologue in Drosophila, is regulated by the $\mathrm{I}-\kappa \mathrm{B}$ family member Cactus and the activation of dorsal drives dorso-ventral polarity formation in developing Drosophila. Whilst many of the regulators of NF- $\kappa B$ have been well studied there undoubtedly remains less well characterised modulators of this important developmental pathway. One such molecule is Cactin. The latter was initially identified in Drosophila as a novel Cactus-interacting protein by using Cactus as bait in a yeast-two hybrid screen (Lin et al., 2000). Drosophila Cactin was shown to be maternally inherited and its over-expression furthered the Cactus mutant phenotype in Drosophila by enhancing embryonic lethality and ventralisation (Lin et al., 2000). The latter study implicates Cactin in the dorsal-ventral pathway and suggests that it positively regulates dorsal function. However no studies have since characterised the developmental role of Cactin and there is no existing data on its function in higher organisms. In the present study we employ zebrafish as a model organism to define for the first time the role of Cactin in vertebrate development. Zebrafish is an especially suitable model for evaluating the importance of Cactin as a novel regulator of NF- $\kappa B$ in development given that NF- $\kappa B$ / $\mathrm{I}-\kappa \mathrm{B}$ members have been previously characterised in zebrafish with inhibition of NF- $\mathrm{KB}$ interfering with notochord differentiation and 
generating no tail-like embryos (Correa et al., 2004). Given this important role for NF- $\kappa \mathrm{B}$ in zebrafish development and the previous characterisation of Cactin as a protein binding partner for the I- $\kappa B$ homologue Cactus we characterised the expression patterns and functional role of zebrafish Cactin in early development.

\subsection{Cloning and bioinformatic analysis of Cactin in zebrafish}

Zebrafish is a genetically tractable model organism, since the entire genome has been sequenced and assembled and this facilitates the assignment of biological gene function (Meeker and Trede, 2008). The known human Cactin sequence was used to search zebrafish genomic sequence data using the BLAST program in the Ensembl Genome database. This search uncovered a zebrafish Cactin orthologue on chromosome 2 . The zCactin gene spans about $13 \mathrm{~kb}$ (kilobases), is composed of 10 exons and is predicted to encode a protein of 771 amino acid (Archive Ensembl GenBank Accession Number LOC567213; see http://oct2007.archive.ensembl.org/Danio_rerio/transview?transcript=ENSDART00000083710\&db=core). In order to examine the evolutionary relationships between Cactin orthologues across an extended taxonomic range, a multiple sequence alignment was constructed (see Supplementary figure). Cactin is highly conserved across species (Fig. 1A). From the multiple alignment it is clear that the $\mathrm{C}$-terminal region of the protein has undergone selective pressure and is highly conserved across the species (Supplementary figure). With the exception of the N-terminal region there is a remarkable overall degree of conservation among the diverse organisms examined indicative of a key role(s) for the protein. A phylogenetic alignment of Cactin orthologues was also generated using ClustalW database (Fig. 1B). Cactin is found throughout eukaryotes in different multicellular animals. Despite the genome-amplification events at the base of vertebrate evolution only a single copy of the Cactin gene is found in the zebrafish genome.

\subsection{Expression of Cactin in early embryonic developmental stages}

The expression patterns of zCactin were next investigated with RT-PCR analysis being performed to characterise expression levels of fully spliced mRNA at various stages of development (Fig. 2A). zCactin mRNA transcript was observed at all stages of early development. Maternal zCactin transcript is also present, since expression is already detected at the 8-cell stage, which is prior to the onset of zygotic gene expression (van der Sar et al., 2006). Interestingly this correlates with the maternal expression of upstream regulators of NF- $\kappa \mathrm{B}$ such as Toll-like receptors and associated adaptor proteins (van der Sar et al., 2006). To determine the spatial and temporal expression of zCactin mRNA in embryonic developmental stages whole mount in situ hybridisation was carried out (Fig. 2B). Embryos were probed with DIG-labelled antisense and sense zCactin RNA. zCactin shows extensive expression from the 8-cell stage to the $48 \mathrm{hpf}$. zCactin expression is not spatially restricted at the 8-

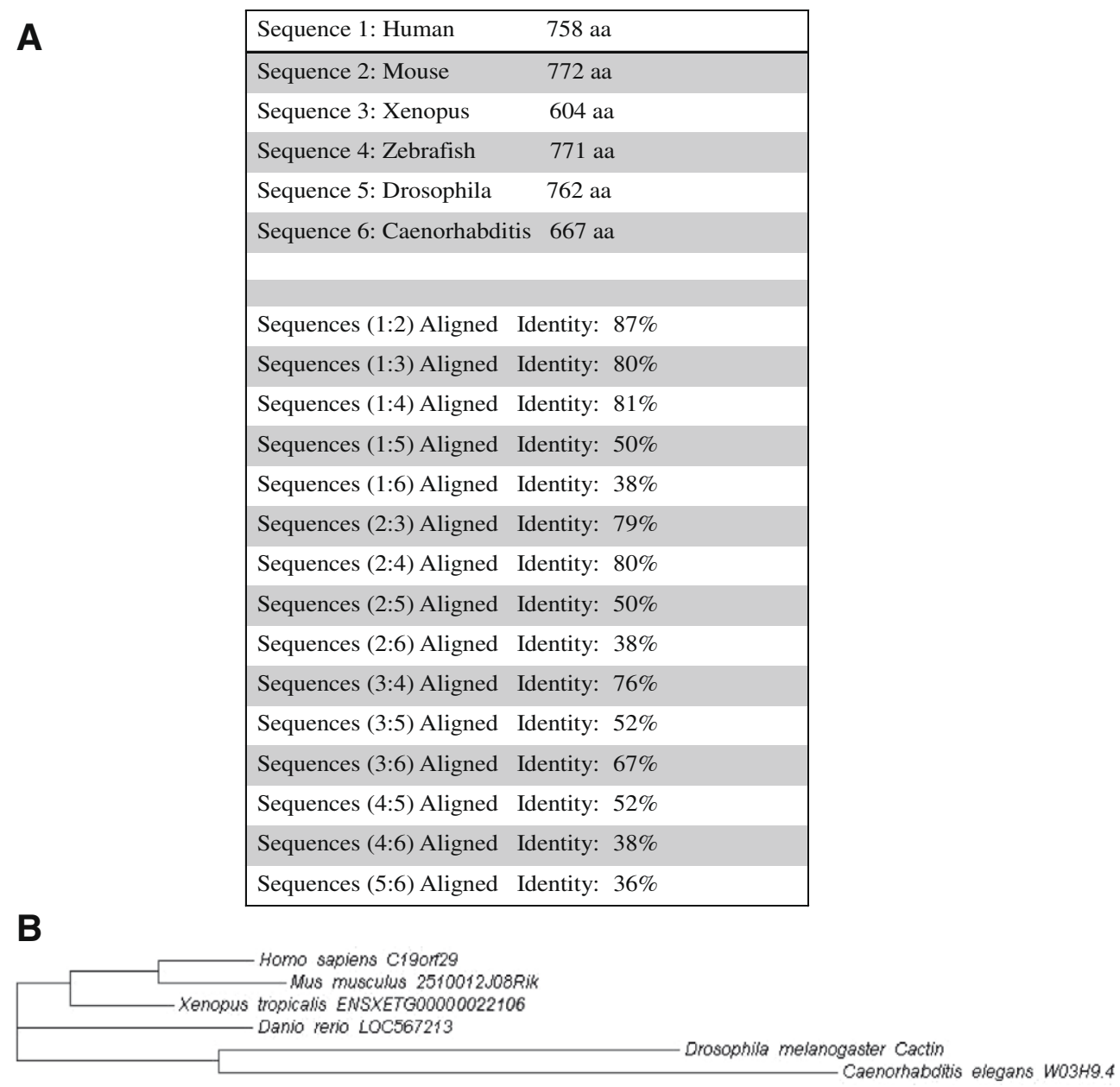

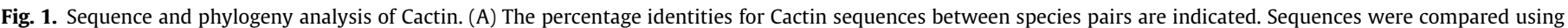

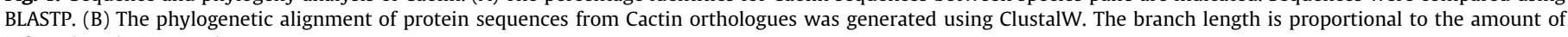
inferred evolutionary change. 
A

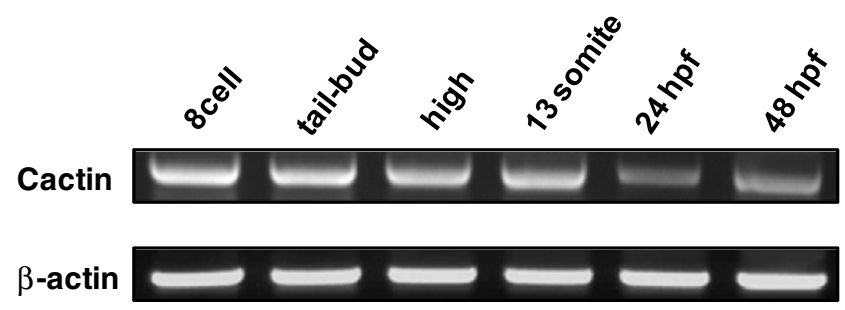

B

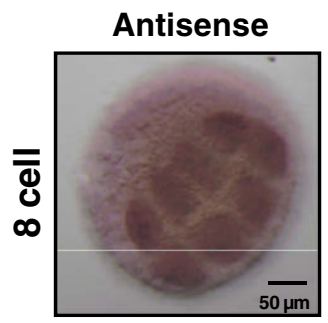

\section{Sense}
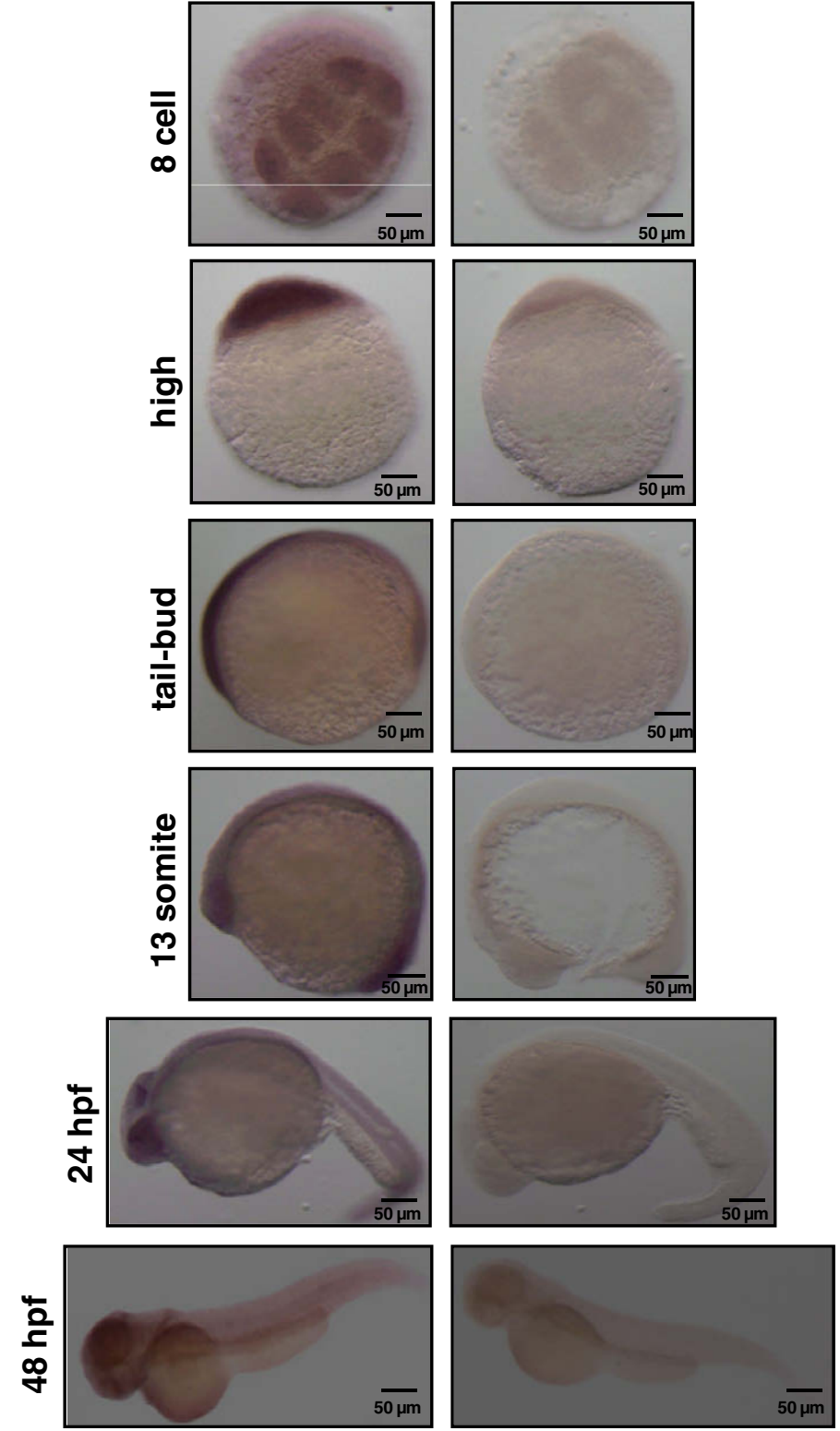

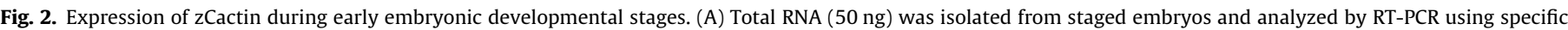

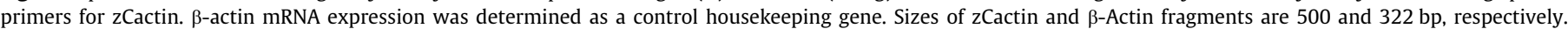

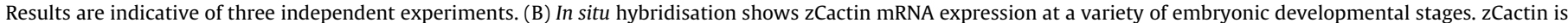

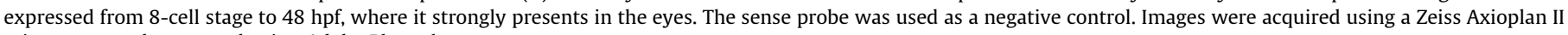
microscope and processed using Adobe Photoshop.

cell to tailbud stage. At the 13 somites stage zCactin expression appears stronger in the eye and the tail and at 24 and $48 \mathrm{hpf}$, there is abundant expression in the eye. The sense probe shows no labelling and was used as a negative control. 
1.3. Knockdown of Cactin by specific morpholino antisense oligonucleotide interferes with early development

To delineate the role of zCactin in early zebrafish development, a morpholino knockdown approach was used to interfere with its expression by inhibition of its mRNA splicing. An antisense morpholino was designed that targets the second intron sequence blocking the splicing between exon 2 and exon 3 (Fig. 3A). A control morpholino was also used. To demonstrate that the zCactin splice-blocking morpholino was truly effective, an RT-PCR strategy was employed. Specific primers targeting exon 2 and exon 3 were designed that spanned the morpholino sequence (Fig. 3B). Semiquantitative RT-PCR revealed that spliced mRNA (as reflected by the 110 bp PCR fragment) is present in control embryos (uninjected or injected with control morpholino), whereas there is an almost complete lack of spliced product in zCactin morpholino injected embryos (Fig. 3B). Interestingly in samples from the latter there are slightly increased levels of a larger PCR fragment ( $\sim 200 \mathrm{bp})$. Whilst the identity of the fragment is unknown it may be representative of an aberrant cDNA resulting from splicing of the mRNA at a site $3^{\prime}$ of the endogenous splice site that is blocked by the zCactin morpholino. For microinjection, morpholi-

A

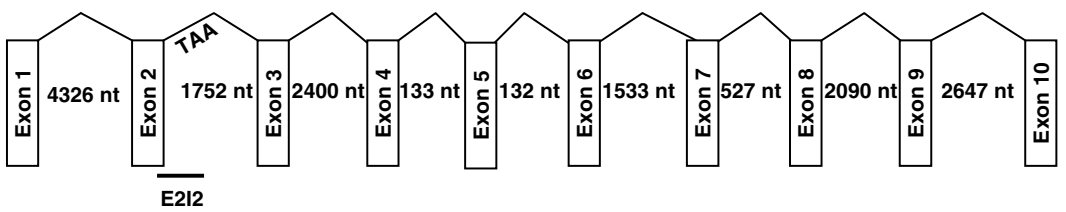

B

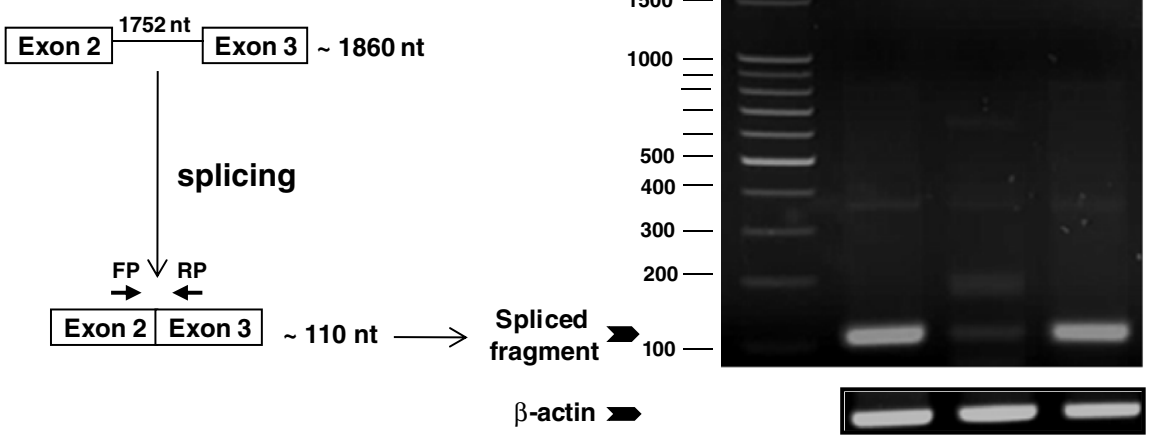

C
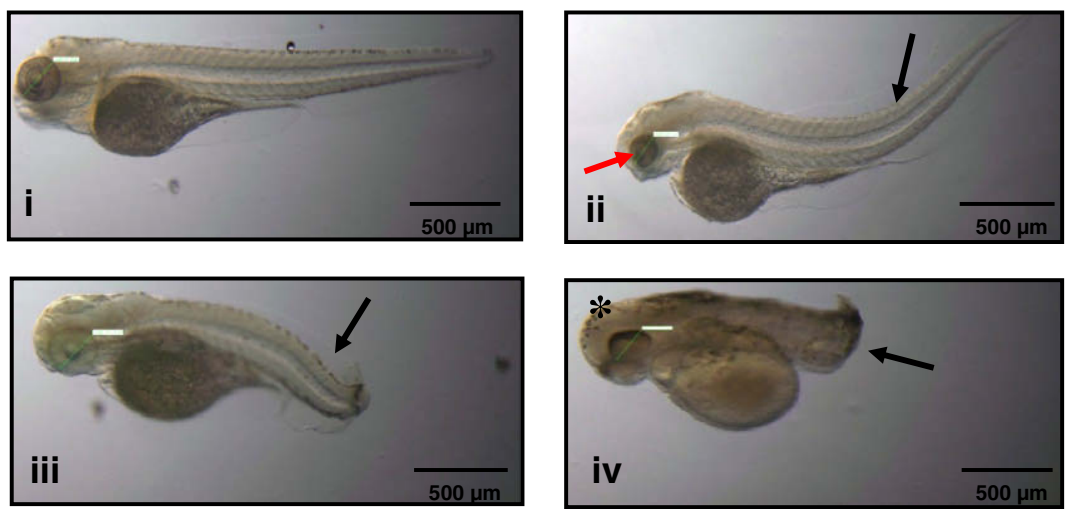

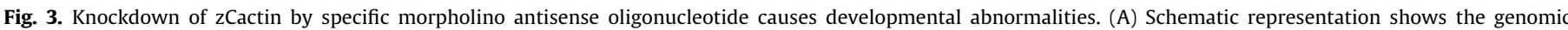

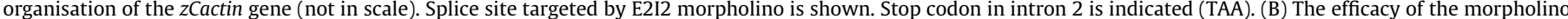

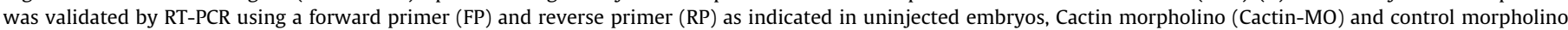

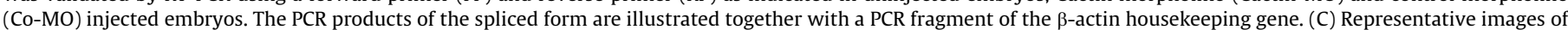

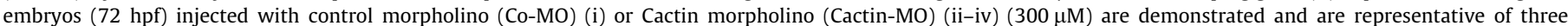

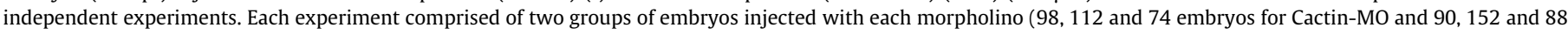

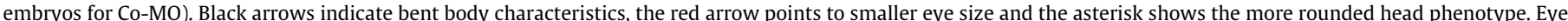

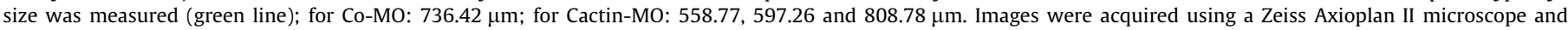
processed using Adobe Photoshop. 
nos were diluted to different concentrations and approximately $1 \mathrm{nl}$ was injected into the blastomere of 1- to 2-cell stage embryo. After $72 \mathrm{~h}$, embryos injected with $300 \mu \mathrm{M}$ zCactin morpholino showed strong phenotypes, including bent body with shortened axis, more rounded head and decreased eye size (Fig. 3C). The phenotypic changes effected by $300 \mu \mathrm{M}$ zCactin morpholino appear to be specific given that such changes were 10 times less frequent in embryos that were injected with control morpholino (Fig. 4A). An increase in the concentrations of either morpholino oligonucleotide led to a loss in specificity. The fundamental importance of zCactin in early development is also apparent from the strong effects of zCactin knockdown on embryonic lethality (Fig. 4B). The injection of embryos with zCactin morpholino oligonucleotide led to $\sim 80 \%$ embryonic lethality even at concentrations as low as $200 \mu \mathrm{M}$ where this level of lethality was only apparent at higher concentrations $(600 \mu \mathrm{M})$ of control morpholino. Such lethality strongly indicates that zCactin plays a fundamental role in early embryonic development. Of the surviving zCactin knockdowns it was especially interesting to observe phenotypes with deficiencies in posterior body morphogenesis, as manifested by bent body and shortened tail characteristics. The effect of the zCactin morpholino with respect to interfering with development of the caudal region is especially intriguing given the well characterised role of NF- $\kappa B$ in the formation of the anterioposterior axis. Thus mutations in the zebrafish gene, no tail ( $n t l)$, are associated with lack of a caudal region (Schulte-Merker et al., 1994) and it is known that NF-кB can bind directly to the $n t l$ promoter and regulate ntl expression (Correa et al., 2004). Furthermore the expression of a dominant negative form of murine $I \kappa B \alpha(\mathrm{mI} \kappa \mathrm{B} \alpha)$, which is able to block NF- $\kappa \mathrm{B}$ in zebrafish cells, or the injection of morpholino oligonucleotides, designed to specifically suppress expression of the NF- $\kappa B$ subunit p65, generates no tail (ntl)-like embryos (Correa et al., 2004). In addition over-expression of I- $\kappa \mathrm{B}$ kinase 1 (IKK 1), an inhibitor of zebrafish NF- $\kappa B$, generates the same phenotype as observed in mI $\kappa \alpha \alpha$ morphants (Correa et al., 2005), suggesting that blocking $\mathrm{NF}-\kappa \mathrm{B}$ affects caudal mesoderm development in zebrafish. Such a developmental role for NF- $\kappa B$ in conjunction with our studies demonstrating that knockdown of zCactin manifests a shortened tail phenotype is consistent with the positive effect of Cactin on Dorsal signalling in Drosophila (Lin et al., 2000).

To define in more detail the developmental abnormalities associated with zCactin knockdown, morphant fish at 72 hpf were sectioned and subjected to light microscopy (Fig. 5). In control fish at 72 hpf the major retinal cell layers have formed (Fig. 5A, C and E)
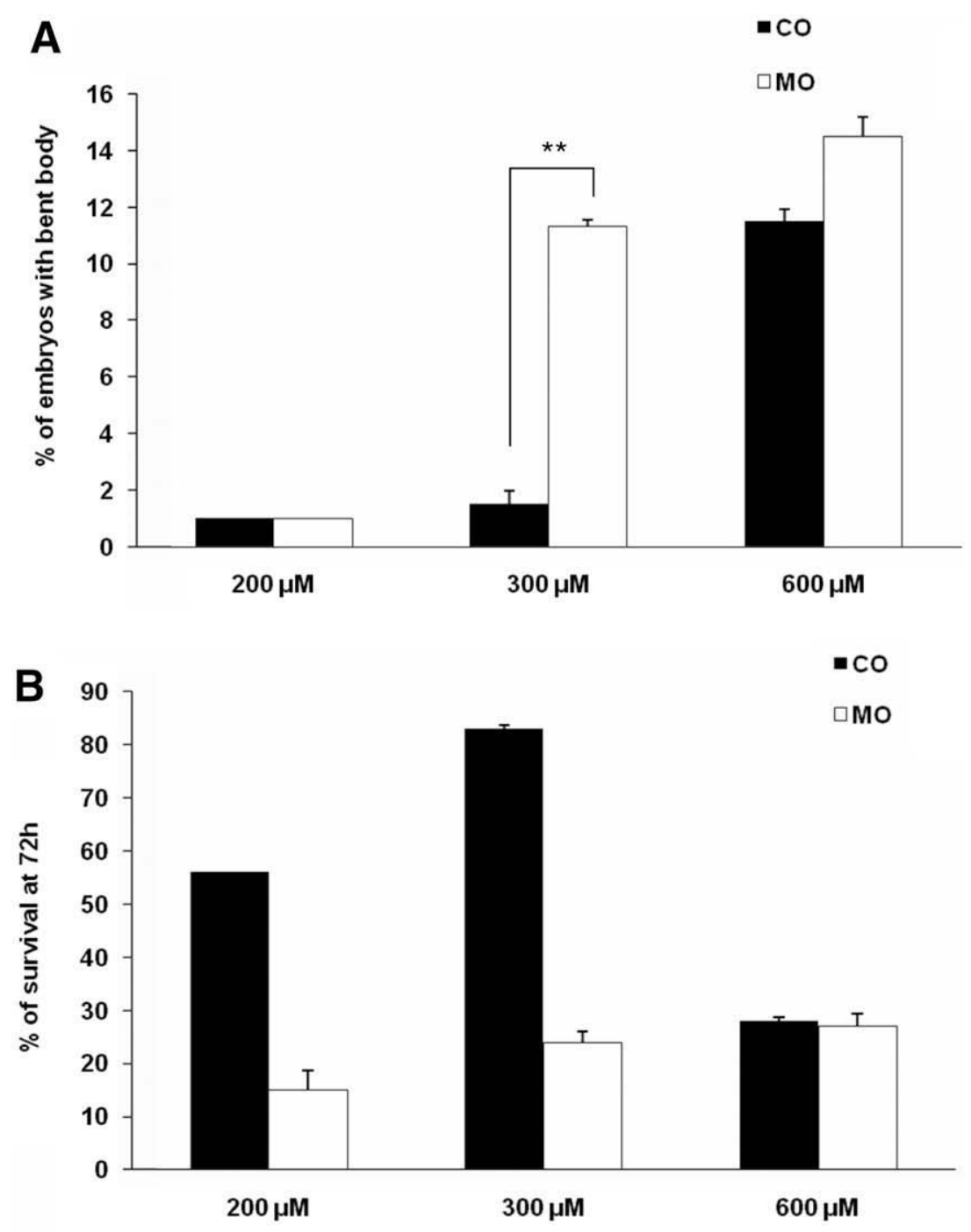

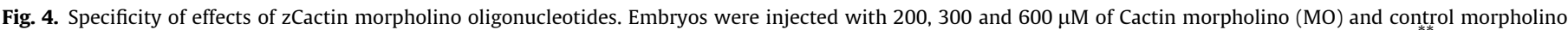

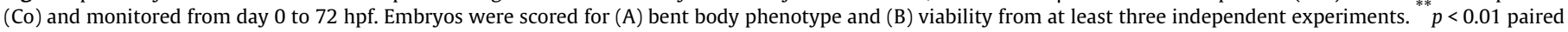
Students $t$ test. 

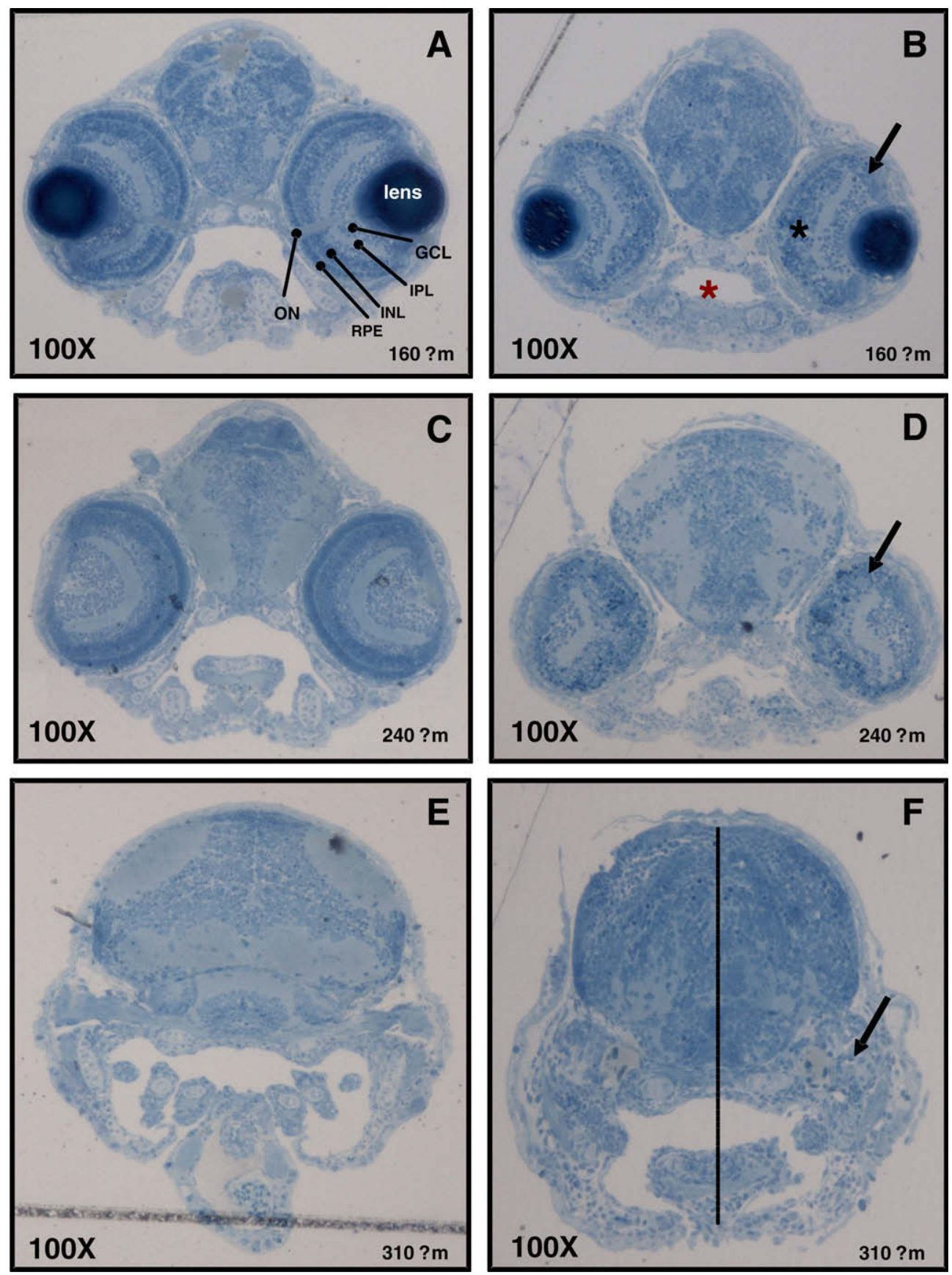

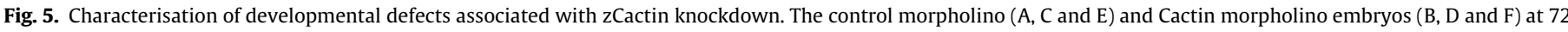

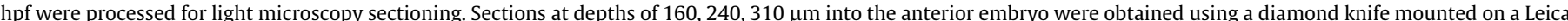

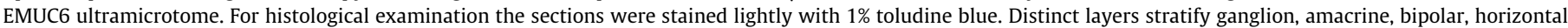

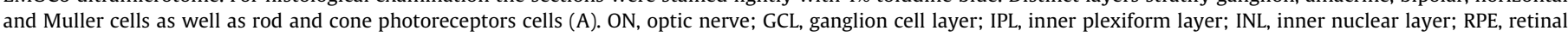

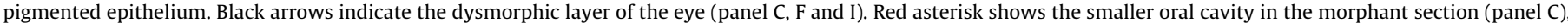

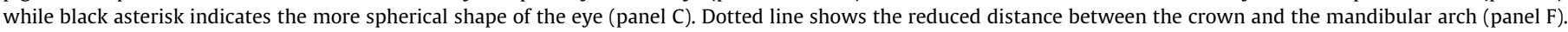
Microscopical images were captured using a Leica DM LB microscope equipped with a Leica DFC 480 digital camera.

including the outer nuclear layer (photoreceptor nuclei), outer plexiform layer, inner nuclear layer (bipolar and amacrines nuclei), inner plexiform layer and ganglion cell layer (Schmitt and Dowling, 1994), whereas there are major defects in the retinal morphology of zCactin knockdown fish (Fig. 5B, D and F). The histological architecture of Cactin morphants is dysmorphic with the eyes being smaller and more spherical and prevalent darkly stained apoptotic nuclei present. The retinal layers display compromised stratification of the retinal layers, especially the outermost layer of the photoreceptor outer segments which appear dishevelled compared to controls.
Interestingly knockdown of zebrafish $i k k 1$ also leads to reduction in eye size (Correa et al., 2005). In the zCactin morphants the oral cavity is also smaller and the distance from crown to the mandibular arches is reduced. Such findings strongly indicate that zCactin plays a role in regulating and controlling neural development.

\subsection{Conclusion}

These studies provide the first detailed characterisation of Cactin expression patterns and function in early development in 
vertebrates. Although, Cactin was originally identified in the Toll dorso-ventral regulatory pathway of Drosophila as a protein that controls Dorsal translocation, the present studies demonstrate that Cactin is involved in the formation of the anterioposterior axis with important roles also in neural development.

\section{Experimental procedures}

\subsection{Zebrafish embryos}

Zebrafish (Danio rerio, Tübingen strain) were maintained according to standard procedures on a $14 \mathrm{~h}$ light/10 h dark lighting cycle at $28.5^{\circ} \mathrm{C}$. Embryos were obtained by natural spawning and developmental stages established by time and morphological criteria (Kimmel et al., 1995). After 48 h, embryo medium was supplemented with $0.003 \%(\mathrm{v} / \mathrm{v})$ phenylthiourea to inhibit melanin synthesis.

\subsection{Sequence analysis}

Human Cactin protein sequence (Accession No. AAX84551) was used as a probe for a BLAST search of the Ensembl zebrafish database (www.ensembl.org/Danio_rerio, (Hubbard et al., 2002). One zebrafish orthologue was identified (Archive Ensembl GenBank Accession Number LOC567213; see http://oct2007.archive.ensembl.org/Danio_rerio/transview?transcript=ENSDART00000083710\&db=core), along with orthologues from Mus musculus (NP_081657), Drosophila melanogaster (NP_523422), Caenorhabditis elegans (NP_496951), Xenopus tropicalis (Q8WUQ7). Protein alignments and phylogenetic tree-building were performed in ClustalW with default setting.

\subsection{In situ hybridisation}

Zebrafish Cactin was amplified by PCR from cDNA using the forward primer 5'-CGGGATCCCGATGGGTGGTTCATCCTCCAAAG-3' and reverse primer 5'-CCGGAATTCCGGTCAACTCTGGACATCTGTG CTG-3'. These primers contain restriction sites for BamHI and Eco$\mathrm{RI}$, respectively, to facilitate cloning into the expression vector pCS2P+. The GC-RICH PCR System (Roche Applied Science) was used for the amplification of the PCR product. Approximately $10 \mu \mathrm{g}$ of the DNA plasmid (zCactin in pCS2P+ vector) was used as template for synthesis of antisense and sense digoxigenin-labelled riboprobes using the DIG in vitro transcription kit with SP6 and T7 polymerases according to the manufacturer's instructions (Roche Applied Science, Indianapolis, IN). Zebrafish embryos were fixed in $4 \%(\mathrm{v} / \mathrm{v})$ formaldehyde/PBS. In situ hybridisation was performed essentially as previously described (Barthel and Raymond, 1993). Embryos were photographed under 100\% glycerol (StereoLumar V12 microscope; Carl Zeiss Meditec Inc. Dublin, CA). Photographs were oriented on computer (Photoshop ver. 5 software; Adobe System). In situ hybridisations were performed in triplicate using between 50 and 100 embryos each time with consistent results. Sense probe failed to produce a detectable background signal.

\subsection{Morpholino knockdown}

Morpholino oligonucleotide (5'-ACCGTATATCATATCTCTCACCT TC $-3^{\prime}$ ) targeting the second intron of zCactin was designed by Gene Tools (Gene Tools LLC, Oregon, USA). A control morpholino ( $5^{\prime}-\mathrm{CC}$ TCTTACCTCAGTTACAATTTATA-3') was also used. Morpholino oligonucleotides were resuspended in nuclease-free water and injected into wild type one- to two-cell zebrafish embryos along with $0.01 \%$ phenol red tracer dye at different concentrations $(200,300$ and $600 \mu \mathrm{M}$ ) by standard technique (Nasevicius and Ekker, 2000). Injected embryos were incubated at $28^{\circ} \mathrm{C}$ for $3-5$ days and scored for altered phenotype. Each experiment comprised of two groups of embryos ( 100 each) injected with control morpholino (cO-MO) or Cactin morpholino (Cactin-MO) carried out three different times with consistent results.

\subsection{PCR analysis}

Total RNA was extracted from zebrafish embryos (TRIzol; Invitrogen) and resuspended in nuclease-free water. The concentration and purity of RNA were measured with a spectrophotometer (NanoDrop Technologies, Wilmington, DE), and contaminating genomic DNA was removed using DNase I (Ambion). RNA was stored at $-80^{\circ} \mathrm{C}$. Reverse transcription was performed on $1 \mu \mathrm{g}$ of total RNA using the Thermoscript RT-PCR system (Invitrogen) at $50{ }^{\circ} \mathrm{C}$ after priming with random hexamers. Synthesised cDNA was stored at $-20^{\circ} \mathrm{C}$. cDNA was used in standard PCR reactions using $1 \mu \mathrm{l}$ cDNA per $25 \mu \mathrm{l}$ PCR reaction. Standard PCR conditions were used, with extension times adjusted to $1 \mathrm{~min}$ per kilobase of target amplicon. The sequences of the primers used are as follows: Cactin forward, 5'-AGAGGGATCTGATGAAGGC-3'; Cactin reverse, 5'-TGTAAAGGGCCTGAAGCTG-3'; $\beta$-actin forward, 5'-GAGA AGATCTGGCATCACAC- $3^{\prime} ; \beta$-actin reverse, $5^{\prime}$-ATCAGGTAGTCTGTCA GGTC-3'; exon-1 morpholino forward, 5'-CGAAGAGTACATGGGCT A-3'; exon 2 morpholino reverse, 5'-CGGACAAATGGCCGATGCC-3'.

\subsection{Light microscopy sections}

Fish (in situ stained or morphants) were fixed in a mixture of $4 \%$ $(\mathrm{v} / \mathrm{v})$ paraformaldehyde and $2.5 \%(\mathrm{v} / \mathrm{v})$ glutaraldehyde diluted in $0.1 \%$ Sorensen phosphate buffer for $1 \mathrm{~h}$ at room temperature. After washing in buffer, all samples were postfixed in $1 \%(\mathrm{w} / \mathrm{v})$ osmium tetroxide in $0.1 \%$ Sorensen phosphate buffer $(\mathrm{pH} 7.3)$ for $1 \mathrm{~h}$ at room temperature followed by washing and dehydration in ascending grades of ethanol to $100 \%$. For histological examination sections were stained lightly with $1 \%(\mathrm{w} / \mathrm{v})$ toluidine blue in $1 \%$ borax and serial sections for colour reactivity were unstained. Images of various magnifications were captured using a Leica DM LB microscope equipped with a Leica DFC 480 digital camera.

\section{Acknowledgements}

The authors thank Dr. David Cottell for technical assistance in light microscopy sections, Sarah McLoughlin for assistance with morpholino design, Beata Sapetto-Rebow for fish care and Dr. Carmel Hensey for critical review of the manuscript. This work was supported by funding from Science Foundation Ireland and the EU Marie Curie action (MNIEST).

\section{Appendix A. Supplementary data}

Supplementary data associated with this article can be found, in the online version, at doi:10.1016/j.gep.2010.03.003.

\section{References}

Barthel, L.K. Raymond, P.A. 1993. Subcellular localization of alpha-tubulin and opsin mRNA in the goldfish retina using digoxigenin-labeled cRNA probes detected by alkaline phosphatase and HRP histochemistry. J. Neurosci. Methods 50, 145-152.

Correa, R.G., Tergaonkar, V., Ng. J.K., Dubova, I., Izpisua-Belmonte, J.C., Verma, I.M., 2004. Characterization of NF-kappa B/I kappa B proteins in zebra fish and their involvement in notochord development. Mol. Cell. Biol. 24, 5257-5268.

Correa, R.G., Matsui, T., Tergaonkar, V., Rodriguez-Esteban, C., Izpisua-Belmonte, J.C. Verma, I.M., 2005. Zebrafish IkappaB kinase 1 negatively regulates NF-kappaB activity. Curr. Biol. 15, 1291-1295.

Govind, S., 1999. Control of development and immunity by rel transcription factors in Drosophila. Oncogene 18, 6875-6887.

Hayden, M.S., West, A.P., Ghosh, S., 2006. NF-kappaB and the immune response. Oncogene 25, 6758-6780 
Hubbard, T., Barker, D., Birney, E., Cameron, G., Chen, Y., Clark, L., Cox, T., Cuff, J., Curwen, V., Down, T., Durbin, R., Eyras, E., Gilbert, J., Hammond, M., Huminiecki, L., Kasprzyk, A., Lehvaslaiho, H., Lijnzaad, P., Melsopp, C., Mongin, E., Pettett, R., Pocock, M., Potter, S., Rust, A., Schmidt, E., Searle, S., Slater, G., Smith, J., Spooner, W., Stabenau, A., Stalker, J., Stupka, E., Ureta-Vidal, A., Vastrik, I., Clamp, M., 2002. The Ensembl genome database project. Nucleic Acids Res. 30, 38-41.

Kimmel, C.B., Ballard, W.W., Kimmel, S.R., Ullmann, B., Schilling, T.F., 1995. Stages of embryonic development of the zebrafish. Dev. Dyn. 203, 253-310.

Lin, P., Huang, L.H., Steward, R., 2000. Cactin, a conserved protein that interacts with the Drosophila IkappaB protein cactus and modulates its function. Mech. Dev. $94,57-65$.

Meeker, N.D., Trede, N.S., 2008. Immunology and zebrafish: spawning new models of human disease. Dev. Comp. Immunol. 32, 745-757.

Minakhina, S., Steward, R., 2006. Nuclear factor-kappa B pathways in Drosophila. Oncogene 25, 6749-6757.
Moynagh, P.N., 2005. The NF-kappaB pathway. J. Cell Sci. 118, 4589-4592.

Nasevicius, A., Ekker, S.C., 2000. Effective targeted gene 'knockdown' in zebrafish. Nat. Genet. 26, 216-220.

Schmitt, E.A., Dowling, J.E., 1994. Early eye morphogenesis in the zebrafish, Brachydanio rerio. J. Comp. Neurol. 344, 532-542.

Schulte-Merker, S., van Eeden, F.J., Halpern, M.E., Kimmel, C.B., Nusslein-Volhard, C., 1994. No tail (ntl) is the zebrafish homologue of the mouse $\mathrm{T}$ (Brachyury) gene. Development 120, 1009-1015.

Vallabhapurapu, S., Karin, M., 2009. Regulation and function of NF-kappaB transcription factors in the immune system. Annu. Rev. Immunol. 27, 693733.

van der Sar, A.M., Stockhammer, O.W., van der Laan, C., Spaink, H.P., Bitter, W. Meijer, A.H., 2006. MyD88 innate immune function in a zebrafish embryo infection model. Infect. Immun. 74, 2436-2441. 